УДК 621.9.06

DOI: https://doi.org/10.26642/ten-2020-1(85)-9-14

В.Н. Волошин, к.т.н., доц.

І.В. Луців, Д.т.н., проф.

В.М. Буховець, к.т.н.

Тернопільський національний технічний університет ім. Івана Пулюя

П.П. Мельничук, д.т.н., проф.

Державний університет «Житомирська політехніка»

\title{
Комплексне технологічне оснащення адаптивного типу для токарної обробки кільцевих деталей
}

\begin{abstract}
Головною проблемою розмірної токарної обробки кільцевих деталей $\epsilon$ недостатня жорсткість заготовки $і$ в иілому технологічної системи. Внаслідок закріплення кільиевих деталей у багатьох випадках їх деформації співрозмірні з допуском на механічну обробку. Тому досягнення заданих параметрів точності форми обробленої поверхні кільцевих заготовок постає складним технологічним та виробничим завданням. Мінімізація похибки обробки можлива лише при правильно вибраних методах обробки і засобах технологічного оснащення. Застосування розробленого комплексного технологічного оснащення, яке включає багаторізцеві пристрої адаптивного типу та відповідні затискні пристрої з рівномірним розподілом зусилля затиску та можливістю його регулювання, є ефективним методом мінімізації пружних деформачій $i$ деформацій внаслідок дії сил різання під час обробки внутрішніх поверхонь кільцевих деталей. Проведено обтрунтування рекомендацій щзодо використання дворізцевого оснащення адаптивного типу під час обробки кільцевих деталей. Запропоновано методику визначення похибки форми циих деталей, яка враховує вплив сил затиску та зусиль різання при обробиі дворізиевим оснащенням. Розроблена методика дозволяє за кінцевим профілем після обробки визначати мінімальну кількість затискних елементів та діапазон прийнятних сил затиску, щзо гарантує необхідний допуск круглості кільцевих цчиліндричних деталей, забезпечуючи їх надійний затиск під час обробки.
\end{abstract}

Ключові слова: комплексне оснащення адаптивного типу; токарна обробка; кільиеві деталі; сили затиску; похибка обробки.

Актуальність теми. Розмірна токарна обробка кільцевих деталей сильно залежить від деформацій оброблюваних поверхонь під дією сил різання і закріплення з подальшим формуванням пов'язаних 3 цим похибок обробки. Головною проблемою при цьому є недостатня жорсткість заготовки і в цілому технологічної системи. Внаслідок закріплення кільцевих деталей у багатьох випадках їх деформації співрозмірні з допуском на механічну обробку. Тому досягнення заданих параметрів точності форми обробленої поверхні кільцевих заготовок $є$ складним технологічним та виробничим завданням. Мінімізація похибки обробки можлива лише за правильно вибраних методів обробки і засобів технологічного оснащення. Вони мають сприяти зменшенню основних похибок, які можуть виникнути на різних стадіях реалізації технологічного процесу обробки маложорстких кільцевих деталей.

Аналіз останніх досліджень та публікації, на які спираються автори. На відміну від однорізцевої обробки багатолезове розточування внутрішніх поверхонь кільцевих заготовок $є$ одним із ефективних методів зменшення макро- і мікропохибок обробки, а також неприпустимих коливань, які виникають під час різання $[1,2]$. Для зменшення впливу сили затиску на точність обробки кільцевих деталей доцільно застосовувати затискні пристрої, що забезпечують: розподіл затискного зусилля за рахунок збільшення кількості точок його прикладання в зоні контакту; розподіл затискного зусилля за рахунок збільшення зони контакту; регулювання затискного зусилля [3-7]. Авторами статті розроблено комплексне технологічне оснащення $[8,9]$, яке включає багатолезове інструментальне оснащення адаптивного типу та відповідні затискні пристрої з рівномірним розподілом зусилля затиску та можливістю його регулювання.

Метою роботи є дослідження можливостей комплексного самоналагоджувального оснащення адаптивного типу для токарної обробки кільцевих заготовок з метою забезпечення підвищення ії ефективності та точності на основі вивчення впливу структури і силових факторів оснащення на результуючі похибки обробки.

Викладення основного матеріалу. Розроблене комплексне технологічне оснащення складається із двох підсистем (рис. 1) [8, 9]. Перша підсистема - це підсистема, яка включає дворізцевий пристрій адаптивного типу. Друга підсистема містить гідравлічний затискний пристрій з рівномірним розподілом зусилля затиску та можливістю його регулювання. Таке оснащення $\epsilon$ ефективним методом мінімізації пружних деформацій і деформацій внаслідок дії сил різання $(y(\theta))$ під час обробки внутрішніх поверхонь кільцевих деталей, де $\theta$ - кут повороту такої деталі. 
При цьому варто мати на увазі, що точність форми при обробці кільцевих деталей значною мірою визначатиметься параметрами системи затиску для їх базування і закріплення. Різні шляхи мінімізації похибок обробки кільцевих заготовок вимагають визначення оптимальної кількості затискних елементів і сили затиску для запобігання провертання деталі під час обробки при забезпеченні іiі деформації в межах допустимих значень.

Доцільно обгрунтувати рекомендації щодо використання дворізцевого оснащення адаптивного типу при обробці кільцевих деталей, яке забезпечує рівність радіальних і тангенціальних складових сил різання. Для цього потрібна аналітична модель формування похибки форми, яка є необхідною для прогнозування результуючого профілю кільцевих деталей при розточуванні дволезовим оснащенням адаптивного типу та їх затиску у гідравлічних затискних пристроях. При цьому слід мати на увазі, що формування відхилення від форми кільцевих циліндричних деталей є наслідком таких основних ефектів: пружної деформації кільця у зв'язку із дією сил затиску; деформацій кільця внаслідок індукованого зусилля в точках прикладання зусилля затиску втулковим затискним елементом із порожнинами, гідравлічного токарного патрона викликаного силами різання [10].

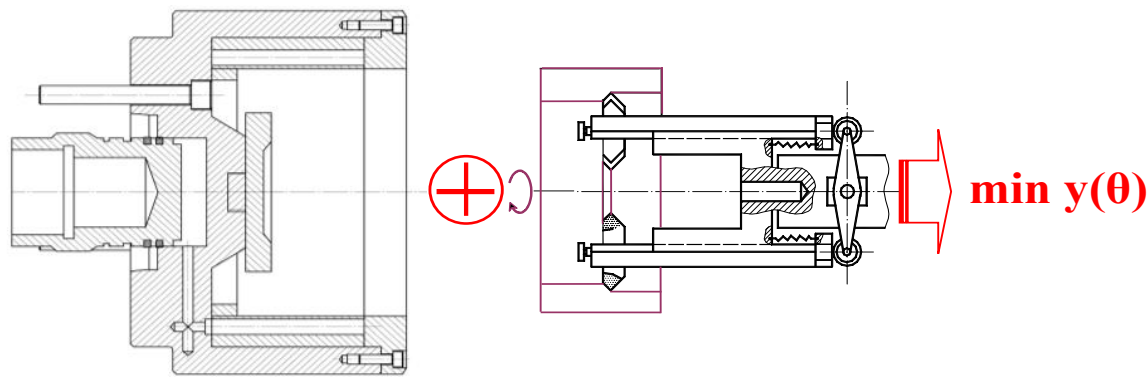

Рис. 1. Схема комплексного технологічного оснащення адаптивного типу для токарної обробки кільиевих деталей

Основою моделі є енергетичний підхід визначення деформації навантаженого тонкостінного кільця зовнішніми зусиллями. Під час розробки моделі були одержані такі припущення: всі сили і відхилення розглядаються в площині кільця, оскільки більшість тонких кілець мають ширину в декілька разів більшу ніж товщину; всі навантаження на кільце розглядаються, як зосереджені; при визначенні енергії деформації використовується радіус $r$, який $є$ середнім значенням внутрішнього і зовнішнього радіусів; матеріал кільця працює в зоні пружних деформацій; місцеві контактні деформації внаслідок дії сил затиску, що діють на кільце, є незначними; радіальні сили затиску втулковим елементом затиску рівномірно розподілені і рівні за величиною.

Для визначення деформації кільцевих заготовок запропоновані розрахункові схеми при зовнішньому навантаженні силами затиску (рис. $2, a$ ) та додатковими силовими навантаженнями, які індукуються в точках прикладання зусилля затиску втулковим затискним елементом і викликані силами різання, що виникають під час обробки дволезовим самоналагоджувальним оснащенням (рис. 2, б).

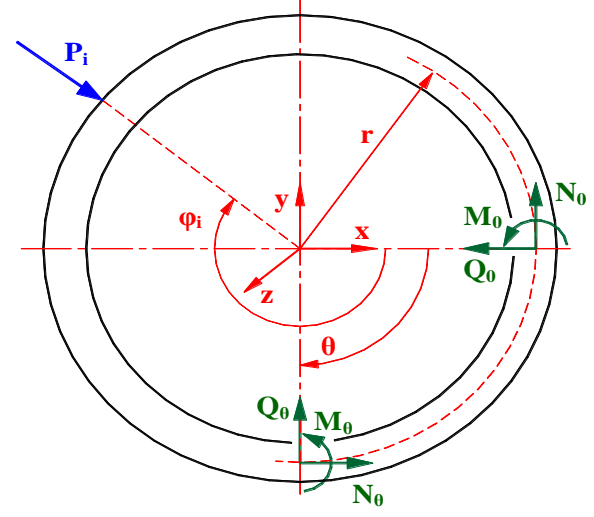

a)

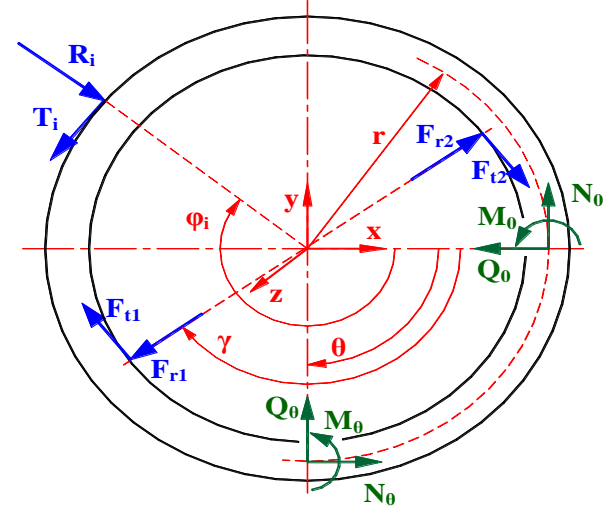

б)

Рис. 2. Розрахункові схеми визначення деформацій кільцевих заготовок при зовнішньому навантаженні силами затиску (а) та додатковими силовими навантаженнями, які індукуються в точках прикладання зусилля затиску втулковим затискним елементом і викликані силами різання (б)

3 врахуванням припущень та на основі розгляду схеми дії силових факторів при затиску кільцевої заготовки силами $P_{i}$ отримані залежності для визначення внутрішніх зусиль у площині перетину кільця $\theta=0$ 


$$
N_{0}=\sum_{i=1}^{n} \frac{\varphi_{i}}{2 \pi} P_{i} \sin \varphi_{i} ; \quad Q_{0}=\sum_{i=1}^{n} \frac{\varphi_{i}}{2 \pi} P_{i} \cos \varphi_{i} ; \quad M_{0}=-r N_{0}-\sum_{i=1}^{n} \frac{P_{i} r}{2 \pi} P_{i},
$$

та будь-якому іншому перетині, що визначається кутом $\theta$ :

$$
\begin{aligned}
& N_{\theta}=N_{0} \cos \theta-Q_{0} \sin \theta+\bar{N}_{\theta} ; \quad Q_{\theta}=N_{0} \sin \theta-Q_{0} \cos \theta+\bar{Q}_{\theta} ; \\
& M_{\theta}=N_{0} r(1-\cos \theta)+Q_{0} r \sin \theta+M_{0}+\bar{M}_{\theta},
\end{aligned}
$$

де $\varphi_{i}-$ кут прикладання сили затиску; $N_{0}, Q_{0}, M_{0}$ - внутрішні зусилля, які діють в площині перетину $\theta=0$ (нормальна сила, поперечна сила та згинальний момент відповідно); $N_{\theta}, Q_{\theta}, M_{\theta}$ - внутрішні зусилля, які діють в площині перетину $\theta$ (нормальна сила, поперечна сила та згинальний момент відповідно); $\bar{N}_{\theta}, \bar{Q}_{\theta}, \bar{M}_{\theta}-$ вектори зовнішніх навантажень, що визначаються силами затиску $P_{i}$, прикладеними в точці $\varphi_{i}$.

Сила затиску $P_{i}$, прикладена в точці $\varphi_{i}$, визначає величини векторів зовнішніх навантажень:

при $0 \leq \theta \leq \varphi_{i}$

$$
\bar{N}_{\theta}=0 ; \bar{Q}_{\theta}=0 ; \bar{M}_{\theta}=0 ;
$$

при $\varphi_{i} \leq \theta \leq 360^{\circ}$

$$
\bar{N}_{\theta}=-P_{i} \sin \left(\theta-\varphi_{i}\right) ; \quad \bar{Q}_{\theta}=-P_{i} \cos \left(\theta-\varphi_{i}\right) ; \bar{M}_{\theta}=-P_{i} r \sin \left(\theta-\varphi_{i}\right) .
$$

Рівняння рівноваги при дворізцевому розточуванні кільцевої заготовки (рис.2,б) можуть бути виражені через складові сил різання $F_{r 1}, F_{r 2}, F_{t 1}, F_{t 2}$ і сил реакції $R_{i}$ та $T_{i}$ в зонах дії сил затиску втулкового затискного елемента:

$$
\left\{\begin{array}{l}
\sum F_{x}=\sum_{i=1}^{n} R_{i} \sin \varphi_{i}+\sum_{i=1}^{n} T_{i} \cos \varphi_{i}-F_{r 1} \sin \gamma-F_{r 2} \sin (\gamma+\pi)-F_{t 1} \cos \gamma-F_{t 2} \cos (\gamma+\pi)=0 \\
\sum F_{y}=\sum_{i=1}^{n} R_{i} \cos \varphi_{i}+\sum_{i=1}^{n} T_{i} \sin \varphi_{i}-F_{r 1} \cos \gamma-F_{r 2} \cos (\gamma+\pi)+F_{t 1} \sin \gamma+F_{t 2} \sin (\gamma+\pi)=0
\end{array},\right.
$$

де $\gamma$ - кут розташування першого різального леза дворізцевого інструментального оснащення адаптивного типу; $r_{6 H}$ - внутрішній радіус кільця; $r_{3 н}-$ зовнішній радіус кільця.

Прийнявши при дворізцевому розточуванні адаптивним оснащенням $F_{r 1}=F_{r 2}=F_{r}$ та $F_{t 1}=F_{t 2}=F_{t}$ та після перетворень із залежності (5) отримаємо

$$
\left\{\begin{array}{l}
\sum F_{x}=\sum_{i=1}^{n} R_{i} \sin \varphi_{i}+\sum_{i=1}^{n} T_{i} \cos \varphi_{i}=0 \\
\sum F_{y}=\sum_{i=1}^{n} R_{i} \cos \varphi_{i}+\sum_{i=1}^{n} T_{i} \sin \varphi_{i}=0
\end{array} .\right.
$$

Як видно із залежності (6) за умови забезпечення адаптивним дворізцевим оснащенням рівності радіальних і тангенціальних складових сил, індукування сил реакції $R_{i}$ та $T_{i}$ в зонах дії сил затиску втулкового затискного елемента відбуватися не буде. Це також продемонстровано на рисунку 3 , на якому наведені деякі позиції кулачків трикулачкового токарного патрона по відношенню до радіальних та тангенціальних складових сил різання при однолезовій та дволезовій обробках.
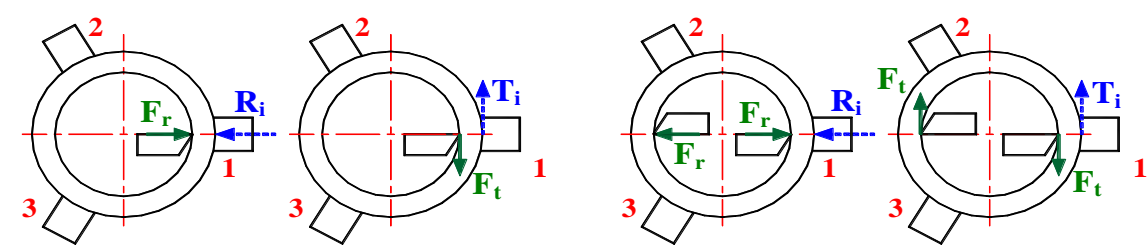

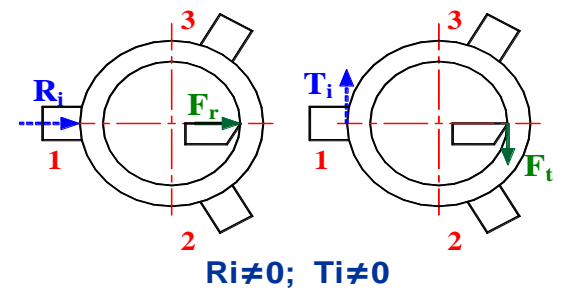

a)

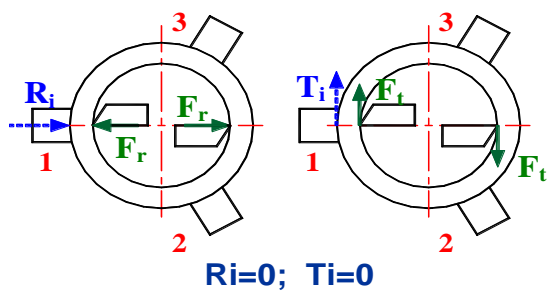

б)

Рис. 3. Умови застосування затиску і обробки та створення на кулачках додаткових радіальних $R_{i}$ та тангенцііальних $T_{i}$ реакиій при однорізцевій (a) і дворізиевій (б) обробках з врахуванням позицій кулачків 
Таким чином, під час використання адаптивного дворізцевого оснащення пружні радіальні деформації кільця будуть визначатися зовнішнім навантаженням тільки від сил затиску, які створюються гідравлічним затискним пристроєм.

Для визначення радіальної деформації кільця $y(\theta)$ при його затиску силами $P_{i}$ використано диференційне рівняння радіальної деформації середньої лінії кільця [10]:

$$
y^{\prime \prime}(\theta)+y(\theta)=-\frac{M(\theta) \cdot r^{2}}{E J},
$$

де $J=r^{3} w \ln (D / d)-r^{2} w((D-d) / 2)$ - момент інерції для прямокутного перерізу кільця із зовнішнім діаметром $D$, внутрішнім діаметром $d$, шириною $w$ і товщиною $t$; Е - модуль пружності другого роду.

Розв'язком диференційного рівняння (7) для $n$ симетрично розташованих і рівних зовнішніх сил $P_{i}$ при $0 \leq \theta \leq 2 \pi / n$ буде вираз:

$$
y(\theta)=-\frac{P_{i} \cdot r^{3}}{2 E J} \cdot\left(\frac{n}{\pi(1+K)}-\left(\frac{C_{1} \theta+1}{2}\right) \sin \theta-\left(\frac{C_{1}}{2}+\frac{C_{1} \pi \cos \frac{2 \pi}{n}}{n \cdot \sin \frac{2 \pi}{n}}+\frac{\pi}{n}-\frac{\theta}{2}\right) \cos \theta\right),
$$

де $K=J / w t \cdot r^{2}$ - коефіцієнт поперечного перерізу кільця; $C_{1}=(1+\cos (2 \pi / n)) / \sin (2 \pi / n)$.

Таким чином, результатами моделювання $€$ радіальні деформації в будь-якій точці кільцевих циліндричних деталей при певних умовах затиску і обробки дворізцевим самоналагоджувальним оснащенням.

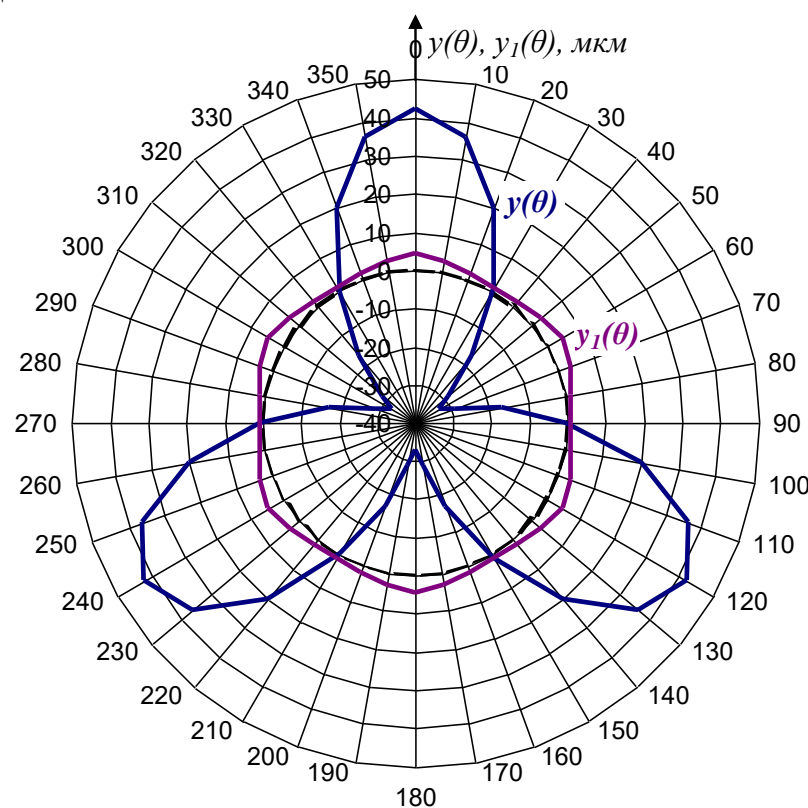

Рис. 4. Радіальні деформачії кільияя в різних кутових положеннях: $y(\theta)$ - при затиску трикулачковим патроном; $y_{1}(\theta)$ - при затиску гідравлічним патроном

Для прикладу у таблиці 1 та на рисунку 4 наведено результати моделювання, отримані в пакеті MathCAD, радіальних деформацій кільця $y(\theta)$ при затиску силами $P_{1}=P_{2}=P_{3}=$ $=3200 \mathrm{H}\left(P_{\Sigma}=9600 \mathrm{H}\right)$ у трикулачковому патроні та радіальних деформацій кільця $y_{1}(\theta)$ при затиску силами $P_{1}=P_{2}=P_{3}=$ $=P_{4}=P_{5}=P_{6}=1600 \mathrm{H}\left(P_{\Sigma}=9600 \mathrm{H}\right) \mathrm{y}$ гідравлічному затискному патроні при обробці дворізцевим оснащенням адаптивного типу. При цьому були прийняті наступні параметри кільця: зовнішній діаметр - 70 мм; внутрішній діаметр - 60 мм; ширина - 18 мм.

Повна теоретична похибка при затиску кільця у трикулачковому токарному патроні складатиме 75 мкм, а при затиску кільця у гідравлічному затискному патроні - 3,9 мкм.

За кінцевим профілем після обробки дворізцевим самоналагоджувальним оснащенням можна визначити значення допустимих сил затиску гідравлічним затискним пристроєм. Такий підхід гарантує отримання необхідного допуску круглості кільцевих циліндричних деталей при забезпеченні їх надійного затиску під час обробки.

Радіальні деформації кільия в різних кутових положеннях при однаковій сумарній Таблиияя 1 силі затиску $P_{\Sigma}=9600$ Н трикулачковим та гідравлічним затискними патронами під час обробки дворізцевим оснащенням адаптивного типу

\begin{tabular}{|c|c|c|c|c|c|c|}
\hline & $\mathbf{0}^{\circ}$ & $\mathbf{1 0}^{\circ}$ & $\mathbf{2 0}^{\circ}$ & $\mathbf{3 0}^{\circ}$ & $\mathbf{4 0}^{\circ}$ & $\mathbf{5 0}^{\circ}$ \\
\hline$y(\theta)$, мкм & 42 & 36 & 20 & 0,51 & -17 & -29 \\
\hline$y_{1}(\theta)$, мкм & 4,4 & 3,25 & 1,35 & 0,5 & 1,35 & 3,25 \\
\hline & $\mathbf{6 0}^{\circ}$ & $\mathbf{7 0}^{\circ}$ & $\mathbf{8 0}^{\circ}$ & $\mathbf{9 0}^{\circ}$ & $\mathbf{1 0 0}^{\circ}$ & $\mathbf{1 1 0}^{\circ}$ \\
\hline$y_{(\theta), \text { мКм }}$ & -33 & -29 & -17 & 0,51 & 20 & 36 \\
\hline$y_{1}(\theta)$ мкм & 4,4 & 3,25 & 1,35 & 0,5 & 1,35 & 3,25 \\
\hline
\end{tabular}


Висновки та перспективи подальших досліджень. Запропонована математична модель формування похибки є рекомендацією для прогнозування форми кільцевих циліндричних деталей при розточуванні з використанням самоналагоджувального дворізцевого інструментального оснащення. Модель дозволяе враховувати багатоточкове прикладання зусилля затиску від затискного пристрою та вплив сил різання від дволезового інструментального оснащення. Така модель доводить, що під час використання дворізцевого самоналагоджувального оснащення додаткові реакції на кулачках від сил різання (при умові забезпечення їх рівності) створюватися не будуть. Аналіз результатів моделювання дозволяє зробити висновок: використання розроблених затискних патронів гідравлічного типу із оболонковими та втулковими затискними елементами суттєво зменшує похибки форми кільцевої деталі від дії сил затиску.

\section{Список використаної літератури:}

1. Технологічне оснащення для високоефективної обробки деталей на токарних верстатах : монографія / Ю.М. Кузнєиов, І.В. Луців, О.В. Шевченко, В.Н. Волошин. - Тернопіль : Терно-граф, 2011. - 692 с.

2. Луців I.В. Дослідження тонкого точіння трирізцевою головкою / I.В. Луц̧ів // Вісник Донбаської державної машинобудівної академії. - 2014. - Вип. 2. - С. 53-56.

3. Зажимные механизмы и технологическая оснастка для высокоэффективной токарной обработки : монография / Ю.Н. Кузнецов, О.И. Драчев, И.В. Лущив и др. - Старый Оскол : ТНТ, 2014. - 480 с.

4. Кузнеиов Ю.Н. Принципы создания станочно-инструментальной оснастки для высокоэффективной токарной обработки : монография / Ю.Н. Кузнещов, О.И. Драчев, В.Н. Волошин. - Старый Оскол : ТНТ, 2016. - 336 c.

5. Lutsiv I. Adaptation of lathe chucks clamping elements to the clamping surface/ I.Lutsiv, V.Voloshyn, R.Bytsa // Machines, Technologies, Materials. International journal. - 2015. - Issue 12. - P. 64-67.

6. Литвин О.В. Дослідження точності обробки кільцевих деталей із зміною вхідних параметрів / О.В. Литвин, В.Г. Кушик // Вісник Національного технічного університету України «Київський політехнічний інститут». Серія : Машинобудування. - 2010. - № 59. - С. 280-284.

7. Sölter J. Influence of clamping strategies on roundness deviations of turned rings / J.Sölter, C.Grote, E.Brinksmeier // Machining Science and Technology: An International Journal. - 2011. - № 15/3. - P. 338-355.

8. Луців І.В. Комп'ютерне моделювання складових самоналагоджувального комплексного оснащення для токарної обробки/ І.В. Луців, В.Н. Волошин, В.М. Буховещь // Вісник Національного університету «Львівська політехніка». Серія : Оптимізація виробничих процесів і технічний контроль в машинобудуванні. $-2012 .-$ Вип. 746. - С. 28-31.

9. Lutsiv I. Ring-shaped parts form accuracy improvement in lathe machining using complex self adjusting equipment / I.Lutsiv, V.Voloshyn, V.Buhovets // Professional Studies: theory and practice. Ser. : Technological Sciences. Lithuania : Siauliai State College. Tallinn University of Applied Sciences. - 2016. - № 1 (16). - P. 80-85.

10. Malluck $J$. Modeling of deformation of ring shaped workpieces due to chucking and cutting forces / J.Malluck, S.Melkote // Journal of Manufacturing Science and Engineering. - 2004. - Vol. 126. - P. 141-147.

\section{References:}

1. Kuznjecov, Ju.M., Luciv, I.V., Shevchenko, O.V. and Voloshyn, V.N. (2011), Tehnologichne osnashhennja dlja vysokoefektyvnoi' obrobky detalej na tokarnyh verstatah, monografija, Terno-graf, Ternopil', 692 p.

2. Luciv, I.V. (2014), «Doslidzhennja tonkogo tochinnja tryrizcevoju golovkoju», Visnyk Donbas'koi' derzhavnoi' mashynobudivnoi' akademii', Issue 2, pp. 53-56.

3. Kuznecov, Ju.N., Drachev, O.I., Luciv I.V. at al. (2014), Zazhimnye mehanizmy i tehnologicheskaja osnastka dlja vysokojeffektivnoj tokarnoj obrabotki, monografija, TNT, Staryj Oskol, 480 p.

4. Kuznecov, Ju.N., Drachev, O.I. and Voloshin, V.N. (2016), Principy sozdanija stanochno-instrumental'noj osnastki dlja vysokojeffektivnoj tokarnoj obrabotki, monografija, TNT, Staryj Oskol, 336 p.

5. Lutsiv, I., Voloshyn, V. and Bytsa, R. (2015), «Adaptation of lathe chucks clamping elements to the clamping surface», Machines, Technologies, Materials. International journal, Issue 12, pp. 64-67.

6. Lytvyn, O.V. and Kushyk, V.G. (2010), «Doslidzhennja tochnosti obrobky kil'cevyh detalej iz zminoju vhidnyh parametriv», Visnyk Nacional'nogo tehnichnogo universytetu Ukrai'ny "Kyi'vs'kyj politehnichnyj instytut», Serija Mashynobuduvannja, No. 59, pp. 280-284.

7. Sölter, J., Grote, C. and Brinksmeier, E. (2011), «Influence of clamping strategies on roundness deviations of turned rings», Machining Science and Technology: An International Journal, No. 15/3, pp. 338-355.

8. Luciv, I.V., Voloshyn, V.N. and Buhovec', V.M. (2012), «Komp'juterne modeljuvannja skladovyh samonalagodzhuval'nogo kompleksnogo osnashhennja dlja tokarnoi' obrobky», Visnyk Nacional'nogo universytetu "L'vivs'ka politehnika», Serija Optymizacija vyrobnychyh procesiv i tehnichnyj kontrol'v mashynobuduvanni, Issue 746, pp. 28-31.

9. Lutsiv, I., Voloshyn, V. and Buhovets, V. (2016), «Ring-shaped parts form accuracy improvement in lathe machining using complex self adjusting equipment», Professional Studies: Theory and Practice, Serija Technological Sciences, Siauliai State College, Tallinn University of Applied Sciences, Lithuania, No. 1 (16), pp. 80-85.

10. Malluck, J. and Melkote, S. (2004), «Modeling of deformation of ring shaped workpieces due to chucking and cutting forces», Journal of Manufacturing Science and Engineering, Vol. 126, pp. 141-147. 
Волошин Віталій Несторович - кандидат технічних наук, доцент, доцент Тернопільського національного технічного університету імені Івана Пулюя.

Наукові інтереси:

- створення і дослідження мобільних затискних систем металорізальних верстатів.

https://orcid.org/0000-0001-8514-9784.

Луців Ігор Володимирович - доктор технічних наук, професор, професор Тернопільського національного технічного університету імені Івана Пулюя.

Наукові інтереси:

- синтез і дослідження верстатно-інструментального оснащення для лезової обробки.

https://orcid.org/0000-0002-3980-428X.

Буховець Валерій Миколайович - кандидат технічних наук, асистент Тернопільського національного технічного університету імені Івана Пулюя.

Наукові інтереси:

- дослідження оснащення для затиску і багаторізцевої обробки.

https://orcid.org/0000-0003-2216-8923.

Мельничук Петро Петрович - доктор технічних наук, професор Державного університету «Житомирська політехніка».

Наукові інтереси:

- технологія машинобудування.

Стаття надійшла до редакції 27.01.2020. 